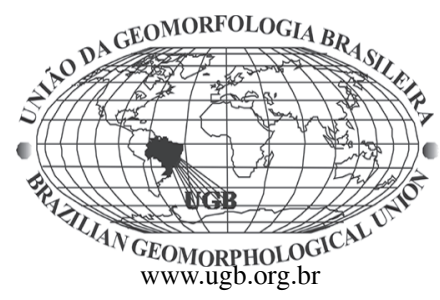

\title{
ASPECTOS GEOMORFOLÓGICOS DE VEREDAS: UM ECOSSISTEMA DO BIOMA DO CERRADO, BRASIL
}

\author{
Cristina H. R. R. Augustin \\ Departamento de Geografia - Instituto de Geociências - UFMG - Av. Antônio Carlos, 6627 - Campus Pampulha - \\ Belo Horizonte-MG - Cep 31270-901 - e-mail: chaugustin@igc.ufmg.br \\ Dirce Ribeiro de Melo \\ Departamento de Geografia - Instituto de Geociências - UFMG - Av. Antônio Carlos, 6627 - Campus Pampulha - \\ Belo Horizonte-MG - Cep 31270-901 - e-mail:veredus2001@yahoo.com.br \\ Paulo Roberto Antunes Aranha \\ Departamento de Geologia - Instituto de Geociências - UFMG - Av. Antônio Carlos, 6627 - Campus Pampulha - \\ Belo Horizonte-MG - Cep 31270-901 - e-mail: aranha@igc.ufmg.br
}

\begin{abstract}
Resumo
As veredas constituem ecossistemas bem definidos que ocorrem no bioma do cerrado brasileiro, e são caracterizadas pela presença do buriti em condições de drenagem pobre. As Veredas também podem ser consideradas feições geomorfológicas, porque elas somente ocorrem ao longo de vales pouco profundos, com baixa energia hidráulica e que alcançam dezenas de quilômetros, interligados aos sistemas de drenagem regionais do centro e de parte do sudeste brasileiros. Embora objeto de várias pesquisas, a complexidade desses geo-ecossistemas ainda não é plenamente entendida. Este estudo foi realizado em uma vereda com o objetivo de contribuir para um melhor entendimento da estrutura e da dinâmica entre as condições superficiais e subsuperficiais e a ocorrência e manutenção da água desses ecossistemas na superfície. A vereda encontra-se localizada em uma superfície de erosão, formada por solos arenosos desenvolvidos sobre arenitos cretáceos, em área com médias anuais de $1.145 \mathrm{~mm}$. Amostras foram coletadas em três perfis de solo, abertos em cada lado do vale e no fundo do canal, ao longo de quatro transectos transversais, posicionados antes do início da cabeceira, no início da cabeceira propriamente dita, no meio curso e a cerca de $400 \mathrm{~m}$ abaixo deste último. Foram realizados radargramas ao longo desses transectos com o auxílio do Georadar (Ground Penetrating Radar-GPR) e abertos três perfis de solo: um em cada lado das bordas, e outro no fundo do vale. Os radargramas indicam a existência de importante sistema de fraturas nos arenitos, indicando que a retenção da água na vereda provavelmente não é advinda da exposição do nível freático regional. Observações de campo e análise dos dados do solo atestam que a presença de umidade do fundo do canal pode estar associada à presença de argila-orgânica, que aparentemente funciona como uma camada tampão, criando condições para a retenção da água na superfície por um período mais prolongado. Sugere, portanto a presença de nível freático suspenso (perched water-table). Os dados também mostram que deposição rápida de colúvio no fundo do canal, está causando o afogamento do fluxo superficial, fazendo com que o nível freático torne-se cada vez mais profundo, o que pode comprometer a preservação desse ecossistema.
\end{abstract}

Palavras-chave: vereda, radargramas, nível freático.

\begin{abstract}
Veredas are well-defined ecosystems that occur within the Brazilian biome of the Cerrado, and are characterized by the presence of Buritis-palm trees in semi-waterlogged conditions. Veredas can also be considered geomorphological features because they only occur along shallow kilometer-long valleys, with their slow flows contributing to the regional drainage systems of central
\end{abstract}


and southeast areas of Brazil. Although being the object of several studies, the complexity of these geo-ecosystems is not yet fully understood. This study was carried out in a Vereda with an aim of providing a better understanding of the structure and dynamics between superficial and underground conditions, and their relation to the maintenance of water on the surface. The Vereda was located on an erosion surface with sandy soils formed over tertiary sandstones, in a semi arid area with annual mean rainfall of $1,045 \mathrm{~mm}$. Samples were collected along three transversal transects placed at the upper head, beginning of head incision, and at middle course. GPR radargrams were produced along each transect and three soil pits were opened, two at each valley side and one at the bottom floor. Radargrams show the presence of important fracture systems in the sandstones indicating that water retained in the Veredas is probably not part of the deep water table. Field observations and soil analysis show the presence of humidity inside the bottom floor soils associated with the presence of organic-clay, which seems to function as a sealing layer that retains water and allows it to stay on the surface during longer periods, similar to a perched water-table. Data also revealed rapid deposition of colluvium at the channel bottom, which is burying the superficial water flow and causing degradation of the ecosystem with the Buritis death.

Keywords: Vereda, radargrams, water table

\section{Introdução}

A gênese e dinâmica de evolução das veredas vêm sendo há muito tempo discutidas por geomorfólogos. Há certo consenso de que as veredas ocorrem tipicamente em chapadas, em áreas deprimidas, ocupadas por fluxo lento de água (FREYBERG, 1967; BARBOSA, 1967; BRANCO, 1961; BOAVENTURA, 1978, 1981, 1988; VIANA 1987; MELO, 1978, 1992, 2008; LIMA, 1996).

A ocorrência de condição de baixa energia hidráulica dos fluxos dos seus canais constitui, aparentemente, um dos aspectos mais relevantes dessas feições geomorfológicas, para a ocorrência do ecossistema associado à presença do buriti (AUGUSTIN et al, 2008). Viana (1987) destaca esse aspecto das veredas na região do Triângulo mineiro ao descrevê-las como zonas encharcadas de fundo chato e baixos gradientes.

Também as condições de alta permeabilidade das camadas superficiais dos solos das áreas de ocorrência das veredas foram apontas como fundamentais para o desenvolvimento desses vales rasos de água quase-parada.

Boaventura $(1978,1981)$, por exemplo, associa a formação de veredas à ocorrência de três condições básicas: existência de superfícies de aplainamento, superposição de camadas geológicas litificadas ou de sedimentos inconsolidados, onde a camada superior é permeável e a inferior impermeável e às condições de exorreísmo. Evidências desse processo, segundo o autor, podem ser observadas no Vale Paracatu, em lagoas ou depressões em fase de interligação. Ele considera que esse processo é resultante de manifestações de exorreísmo, que sucedeu as pediplanações.

Dados climáticos da região estudada, no entanto, indicam a ocorrência de pluviosidade média relativamente baixa, com médias anuais de $1.145 \mathrm{~mm}$, e temperaturas elevadas com médias anuais de $24,7^{\circ} \mathrm{C}$ e máximas que frequentemente ultrapassam $35^{\circ} \mathrm{C}$, o que implica na ocorrência de altas taxas de evapotranspiração. As condições climáticas apontam para uma carência hídrica da área, sendo difícil encontrar, nessa situação, o nível freático que aflore em toda a extensão da ocorrência das veredas.

O presente artigo estuda uma dessas veredas buscando identificar, a partir da análise de radargramas obtidos com o uso do Georadar e de perfis de solos, a relação entre as características superficiais e subsuperficiais, e as condições hídricas e de evolução do seu canal.

Devido à versatilidade e operacionalidades do GPR, este vem sendo aplicado a diversas áreas de estudos, geoctecnia, hidrogeologia, contaminação, estruturação do solo e outros (BENSON, 1995; DAVIS et al, 1989; HARA et al, 1985; HUGGENBERGER et al, 1994).

Em Minas Gerais, o Georadar tem sido utilizado no estudo geomorfológico em diversos lugares, dentre eles na região de Gouveia (ARANHA, 2003; ARANHA et al, 2003; AUGUSTIN et al, 2005), com importantes contribuições.

\section{Caracterização da Área de Estudo}

A área de estudo situa-se num planalto arenítico do norte do estado de Minas Gerais (denominado por Melo (2008) como Planalto Areado), no município de Buritizeiro (Fig. 1), o quinto maior do estado com área de $7.249 \mathrm{Km}^{2}$. Situa-se à margem esquerda do rio São Francisco e apresenta uma densa rede de drenagem representada em sua grande parte por rios, cujas nascentes são veredas (Baggio, 2002).

O relevo dominante é representado por extensa superfície suavemente ondulada, que faz parte do planalto modelado sobre arenitos cretáceos do Grupo Areado e que recobre as rochas Proterozóicas do Grupo Bambuí. O Grupo Areado, do Cretáceo Inferior, está depositado diretamente sobre as rochas do Grupo Bambuí, constituído por conglomerados arenosos na base, arenitos conglomeráticos com quartzito e quartzo faceto-ventefactos e por arenitos de matriz silicosa, de cor róseo-avermelhado (CETEC, 1981). 
Aspectos geomorfológicos de veredas: um ecossistema do bioma do cerrado, Brasil.

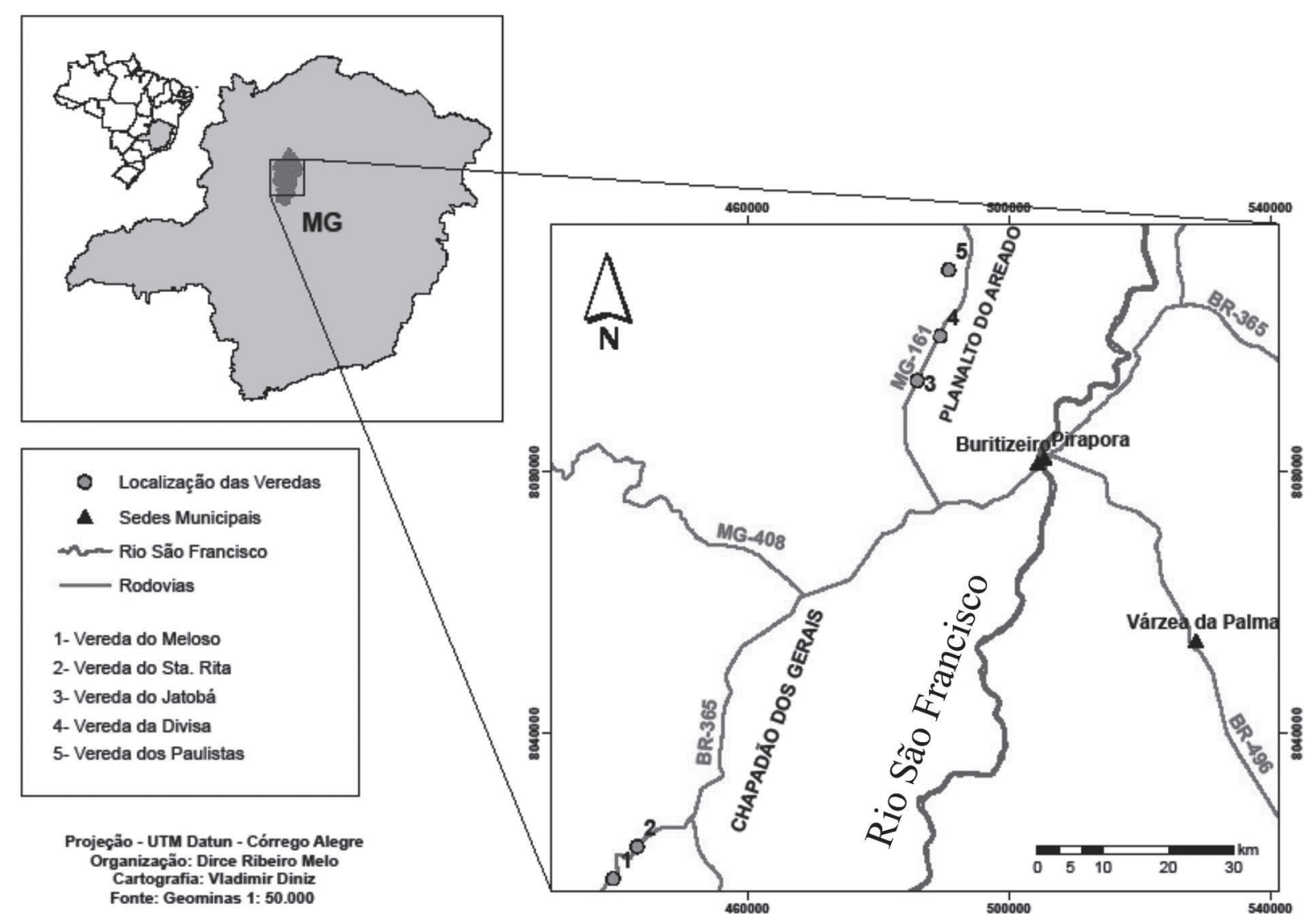

Figura 1 - Localização da área de estudo- vereda Jatobá

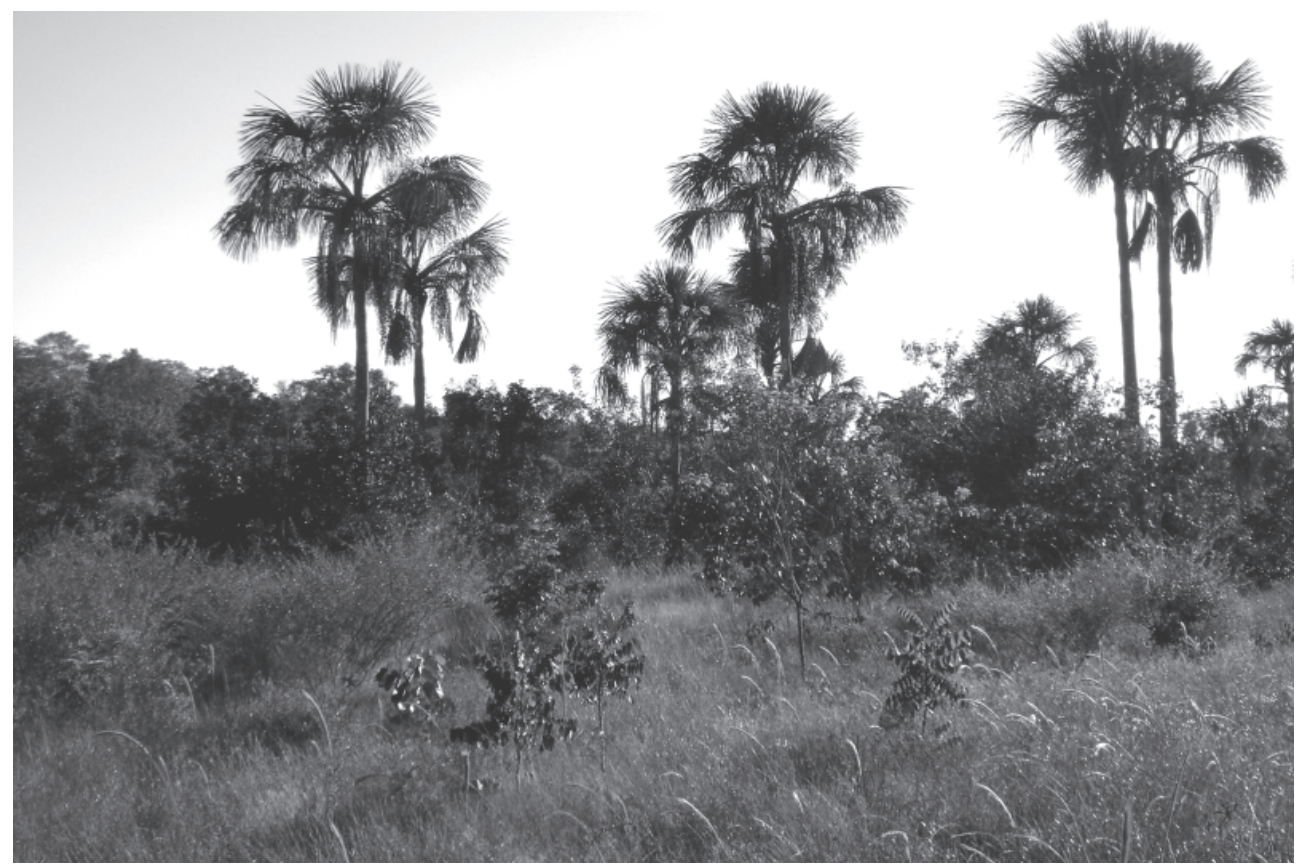

Figura 2 - Vegetação típica de vereda com a presença de buritis 
De acordo com a classificação de Köppen, o clima da área é do tipo AW, ou seja, quente e úmido com chuvas de verão. A precipitação média anual é de 1.145 mm (estação de Pirapora), concentrada de outubro a março. A temperatura média anual é de $24,7^{\circ} \mathrm{C}$, embora a média dos meses mais quentes oscile entre 24,1 e $25,3^{\circ} \mathrm{C}$, enquanto a média dos meses mais frios (junho e julho) fica em $19,7^{\circ} \mathrm{C}$. As máximas anuais, no entanto, podem ultrapassar $35^{\circ} \mathrm{C}$ (CETEC, 1981).

"A vereda estudada foi denominada por Melo (2008) de Jatobá, localiza-se entre as coordenadas $17^{\circ} 14^{\prime} \mathrm{S}$ e $45^{\circ} 05^{\prime} 56,6^{\prime \prime} \mathrm{W}$, e apresenta altitude entre 730 e $715 \mathrm{~m}$.

A vegetação original dominante era o Cerrado, desde sua fisionomia mais aberta (campos limpos) até as mais densas (cerradão), passando por várias fases de degradação do cerrado. No meio do Cerrado, aparece o bioma da vereda, no qual predomina os buritis (Fig. 2). Adjacente à vereda é possível observar, em sua borda direita, um cerrado em fase de incipiente regeneração, onde Melo (1992) registrou, tanto em 1978 como em 1992, o uso com monocultura de eucalipto. Atualmente o eucaliptal encontra-se à distância de $80 \mathrm{~m}$ da vereda (Melo, 2008).

\section{Metodologia}

A escolha da Vereda Jatobá ocorreu após trabalho de campo, para definição da amostragem. Em fase posterior, foi realizado novo campo no qual foram descritos e amostrados os principais aspectos e características que pudessem levar a um melhor entendimento dos processos e fases evolutivas da vereda. Para isto, foram realizados quatro transectos transversais ao perfil longitudinal da vereda: o primeiro à $50 \mathrm{~m}$ acima da cabeceira; o segundo, na cabeceira propriamente dita; o terceiro, no meio curso, e o quarto, a cerca de $400 \mathrm{~m}$. do terceiro transecto. Ao longo de cada transecto, foram abertos perfis de solos para descrição e coleta de amostra, medidas de vegetação e de radargramas (Fig. 3). Por tratar-se de uma vereda muito extensa, com cerca de $5 \mathrm{~km}$ antes de desaguar no rio Jatobá, não foi possível a amostragem de um número maior de perfis transversais.

Em cada transecto, foram realizadas observações sobre a cobertura vegetal, a ocorrências de processos erosivos, além da abertura de perfis de solo acompanhados pela realização de perfis subsuperficiais (radargramas), utilizando-se o Ground Penetrating Radar (GPR ou Georadar). Os perfis de solos foram descritos com o auxílio do Manual de Descrição e Coleta de Solo no Campo (LEMOS et al, 1992) e amostras coletadas para análises. As análises, realizadas no laboratório de Geomorfologia do Instituto de Geociências, UFMG, compreenderam: textura, percentagem de matéria orgânica e umidade atual. Para as análises granulométricas utilizou-se o método de pipetagem. A matéria orgânica foi medida através do método de Walkley \& Black (1947). Houve medição da umidade atual (gravimétrica) de cada horizonte, definida pela alteração do peso da amostra (50gr) antes e após período de 24 horas de secagem em estufa à temperatura de $105 \mathrm{a} 110^{\circ} \mathrm{C}$ e resfriamento em dessecador.

A umidade foi calculada da seguinte forma: peso da amostra úmida - peso da amostra seca, peso da mostra seca x 100 (EMBRAPA, 1997). As cores foram identificadas a partir do Munsell Color Chart. A campanha geofísica realizou-se através da obtenção de quatro perfis de Georadar acompanhando os transectos, com o equipamento RAMAC, da Mala GeoScience. Concomitante, perfis CMP foram obtidos para a definição do perfil velocidade da onda EM na área investigada, nos quais foram utilizadas antenas de baixa frequência - 100MHz. O levantamento foi executado com antenas a distância constante (common offset), no qual o sistema é transportado ao longo de uma direção obtendo-se um perfil das reflexões versus posição. Foi utilizado o modo de 8 stacks, com o objetivo de aumentar a relação sinal/ ruído da onda emitida, melhorando a qualidade dos dados adquiridos no campo.

Os demais parâmetros utilizados para a elaboração dos perfis foram: frequência de amostragem aproximadamente 10 vezes a frequência central da antena utilizada; janela de tempo de $400 \mathrm{~ms}$; a frequência central utilizada foi de $100 \mathrm{MHz}$. O espaçamento entre os pontos de aquisição de dados foi de $0,10 \mathrm{~m}$ para a antena de $100 \mathrm{MHz}$.

O processamento de dados objetivou melhorar a qualidade dos resultados obtidos no campo, para que a interpretação das imagens apresentasse melhor precisão. A edição compreendeu a organização dos dados, sua correção, o posicionamento das linhas etc. Tratamentos mais avançados foram aplicados aos dados tais como declipping, filtragem, marcação do "tempo zero", ganhos temporais e correção topográfica, migração dos dados (ARANHA, 2003).

\section{Apresentação e Discussão dos Resultados}

Foi aberto apenas um perfil de solo ao longo do primeiro transecto do GPR (Fig. 4), realizado perpendicular ao perfil longitudinal da vereda do Jatobá, à 50m do início da cabeceira.

Os dados desse perfil de solo (Tab.1) indicam a presença de material argilo/siltoso nos $6 \mathrm{~cm}$ superiores do perfil e arenoso escuro a esverdeado nas profundidades abaixo desta (FOR GLEY 3/5G). As cores esverdeadas indicam a ocorrência de drenagem pobre, o que foi comprovado pelos dados do GPR, que identificou o nível freático relativamente superficial ( 55 a $65 \mathrm{~cm}$ de profundidade), presente muito antes do início da vereda. Esta é uma área sazonalmente encharcada, revelando o fato de que a vereda apresenta um processo contínuo de formação para montante, enquanto permanecerem presentes as condições para o seu desenvolvi- 
mento. O material superior encontrado sobre o solo hidromórfico permite identificar a ocorrência de colúvio (primeiros $6 \mathrm{~cm}$ ), resultado da erosão superficial da água de chu- va. A ausência de umidade real abaixo dos centímetros iniciais do solo parece estar relacionada à textura arenosa do material, que impede a retenção da água.

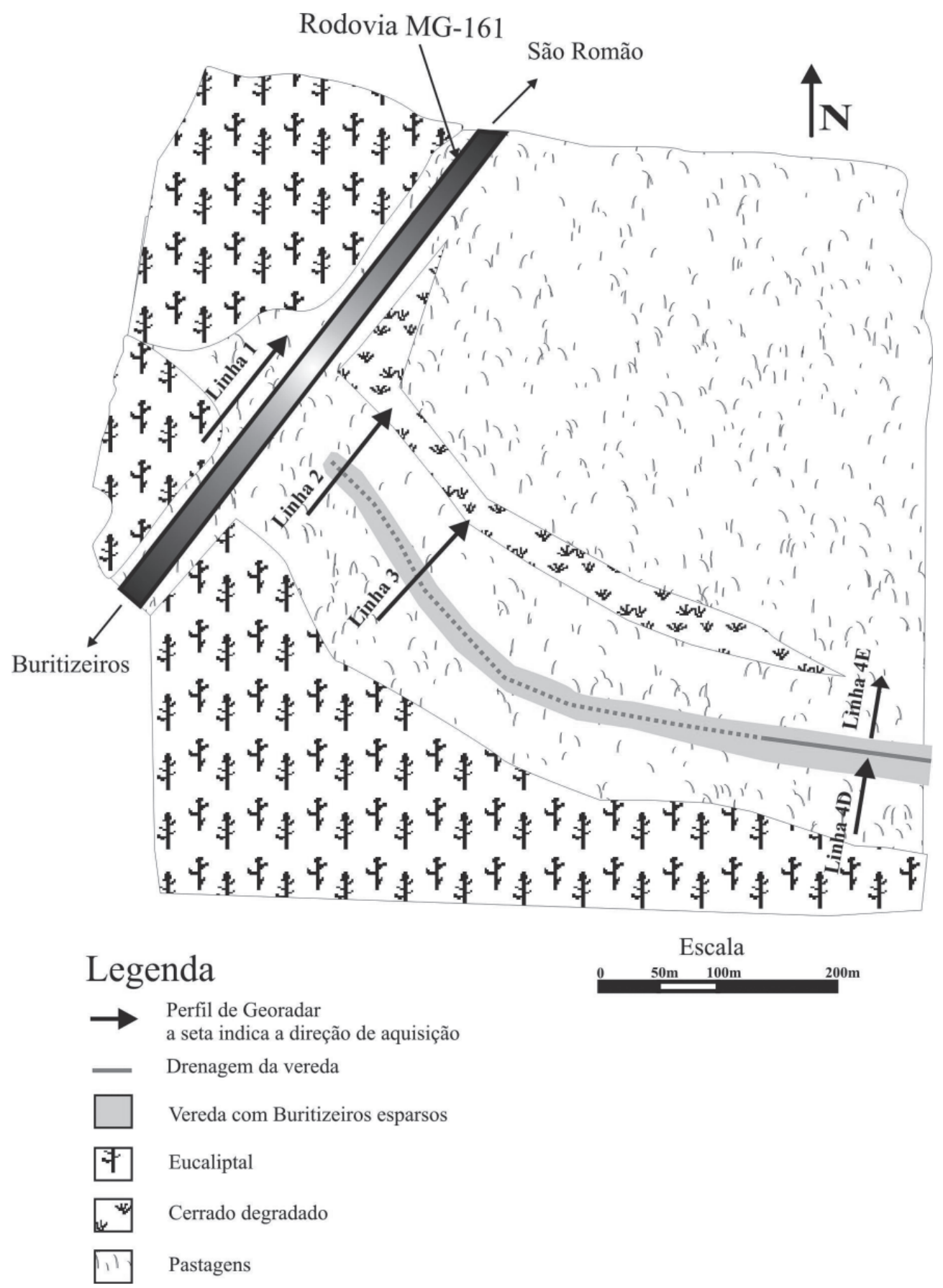

Figura 3 - Mapa de localização dos perfis de Georadar ao longo da vereda Jatobá 
Tabela 1 - Características dos Isovolumes da Vereda do Jatobá - Buritizeiros-MG/setembro-outubro/2007

\begin{tabular}{|c|c|c|c|c|c|c|c|c|}
\hline $\begin{array}{l}\text { Transecto } \\
\text { Número: }\end{array}$ & $\begin{array}{l}\text { Perfil } \\
\text { Solo }\end{array}$ & Isovolume & Profundidade $(\mathrm{cm})$ & $\begin{array}{c}\text { Textura } \\
\text { Classificação }\end{array}$ & $\begin{array}{c}\text { Matéria } \\
\text { Orgânica } \\
\text { \% }\end{array}$ & $\begin{array}{l}\text { Unidade } \\
\text { atual }\end{array}$ & Cor & $\begin{array}{c}\text { Observações } \\
\text { Gerais }\end{array}$ \\
\hline \multirow{4}{*}{$\begin{array}{c}1 \\
50 \mathrm{~m} \text { acima } \\
\text { do início da } \\
\text { vereda }\end{array}$} & \multirow[t]{3}{*}{$\begin{array}{c}1 \\
\text { fundo do } \\
\text { canal da } \\
\text { vereda }\end{array}$} & a & $0-6$ & Argilo-siltoso & & & 5YR 4/6 & $\begin{array}{l}\text { colúvio } \\
\text { vermelho- } \\
\text { amarelo } \\
\text { deposição } \\
\text { recente }\end{array}$ \\
\hline & & $\mathrm{b}$ & $6-16$ & $\begin{array}{c}\text { Franco-argilo } \\
\text { arenosa }\end{array}$ & 3,5 & 1,7 & $\begin{array}{c}\text { FOR GLEY } \\
3 / 5 \mathrm{G} \\
\end{array}$ & \\
\hline & & $\mathrm{c}$ & Abaixo de 26 & areia & $\mathrm{O}, 3$ & 0,0 & $\begin{array}{c}\text { FOR GLEY } \\
8 / 10 \mathrm{Y} \\
\end{array}$ & \\
\hline & \multicolumn{8}{|c|}{ LENCCOL FREÁTICO ENCONTRADO A $55 \mathrm{~cm}$} \\
\hline \multirow{6}{*}{$\begin{array}{c}2 \\
\text { ao longo dos } \\
1^{\circ} \text { Buritis }\end{array}$} & \multirow{3}{*}{$\begin{array}{c}1 \\
\text { (borda } \\
\text { direita da } \\
\text { vereda) }\end{array}$} & a & $0-12$ & areia & & & 10 YR $6 / 8$ & $\begin{array}{l}\text { Colúvio } \\
\text { deposição } \\
\text { recente }\end{array}$ \\
\hline & & $\mathrm{b}$ & $12-25$ & areia franca & 3,1 & 0,4 & 2.5 YR $3 / 1$ & \\
\hline & & $\mathrm{c}$ & $25-45$ & areia & 0,6 & 0,1 & 5 YR $7 / 1$ & \\
\hline & \multirow{2}{*}{$\begin{array}{c}2 \\
\text { (fundo } \\
\text { do canal } \\
\text { da } \\
\text { vereda) } \\
\end{array}$} & a & $0-85$ & areia & 2,5 & 0,5 & 5 YR 4/6 & colúvio \\
\hline & & $\mathrm{b}$ & $85-1,85$ & argilo-siltosa & 27,4 & 86,7 & $\begin{array}{c}\text { FOR GLEY } \\
2.5 / \mathrm{N}\end{array}$ & $\begin{array}{c}\text { turfa } \\
\text { organosolo }\end{array}$ \\
\hline & \multicolumn{8}{|c|}{ LENCCOL FREÁTICO ENCONTRADO A $188 \mathrm{~cm}$} \\
\hline \multirow{5}{*}{$\begin{array}{c}3 \\
\text { (realizado } 1 \\
\text { única } \\
\text { abertura de } \\
\text { perfil de solo } \\
\text { no fundo do } \\
\text { canal da } \\
\text { vereda) }\end{array}$} & \multirow{4}{*}{$\begin{array}{c}2 \\
\text { (zona } \\
\text { central da } \\
\text { vereda) }\end{array}$} & a & $0-5$ & argila & 23,5 & 11,3 & 5 YR $3 / 3$ & $\begin{array}{c}\text { ocupado por } \\
\text { braquiária }\end{array}$ \\
\hline & & $\mathrm{b}$ & $5-55$ & argila & 28,6 & 114,7 & $\begin{array}{c}\text { FOR GLEY } \\
2,5 / \mathrm{N} \\
\end{array}$ & \\
\hline & & c & $55-110$ & argila & 17,4 & 92,5 & $\begin{array}{c}\text { FOR GLEY } \\
2,5 / \mathrm{PB} \\
\end{array}$ & \\
\hline & & d & $110-210$ & argila & 16,4 & 80,6 & $\begin{array}{c}\text { FOR GLEY } \\
2,5 / \mathrm{PB}\end{array}$ & \\
\hline & & & LENÇOL & EÁTICO ENCC & RADO A & $0 \mathrm{~cm}$ & & \\
\hline \multirow{6}{*}{$\begin{array}{c}4 \\
\text { (borda direita } \\
\text { de vereda) }\end{array}$} & $\begin{array}{c}1 \\
(\text { alta } \\
\text { vertente) }\end{array}$ & a & $0-100$ & areia & & olo hidrome & ico & gley \\
\hline & \multirow{2}{*}{$\begin{array}{c}2 \\
\text { (baixa } \\
\text { vertente) }\end{array}$} & a & $0-25$ & franco-argilosa & 6,1 & 13,3 & $\begin{array}{c}\text { FOR GLEY } \\
3 / \mathrm{N}\end{array}$ & $\begin{array}{l}\text { gramíneas } \\
\text { verdes e } \\
\text { arbustos }\end{array}$ \\
\hline & & $\mathrm{b}$ & $25-34$ & areia & & & Cinza escuro & \\
\hline & \multirow{2}{*}{$\begin{array}{c}3 \\
\text { fundo do } \\
\text { "canal" } \\
\text { da vereda }\end{array}$} & a & $0-50$ & argila & & 103,8 & $\begin{array}{c}\text { FOR GLEY } \\
2.5 / 10 \mathrm{G}\end{array}$ & $\begin{array}{c}\text { muitas raízes } \\
\text { e campo de } \\
\text { gramíneas }\end{array}$ \\
\hline & & $\mathrm{b}$ & $50-60$ & areia & 0,5 & 5,7 & $\begin{array}{c}\text { FOR GLEY } \\
7 / 10 \mathrm{Y} \\
\end{array}$ & \\
\hline & \multicolumn{8}{|c|}{ LENÇOL FREATTICO ENCONTRADO ABAIXO DE $60 \mathrm{~cm}$} \\
\hline
\end{tabular}

Essa interpretação é corroborada pelas imagens do radargrama obtidas ao longo da Linha 1 (Fig. 4 a), pois os refletores mais próximos à superfície podem ser correlacionados com eventos deposicionais recentes. No radargrama é possível observar o material coluvial e, dentro dele, os refletores indicam a presença de uma superfície deposicional ainda mais recente.

Entre as distâncias de 55 e $65 \mathrm{~m}$, numa profundidade de $1 \mathrm{~m}$ ocorre a atenuação da onda EM, apontando para a presença de material saturado. É interessante notar na parte superior do radargrama, refletores com ligeiro abaulamento no centro, mostrando a zona preferencial de acúmulo de água. Esse abaulamento pode estar associado ou ao lento, mas contínuo processo de erosão fluvial, ou à existência de zonas preferenciais de dissolução da sílica. Ele é representativo, na medida em que parece apontar para um recuo da cabeceira da vereda à montante, ao longo de um alinhamento preferencial do processo de evolução da drenagem. Logo abaixo dos refletores mais horizontalizados, observa-se um intrincado desenho de refletores planos, 
curtos, cortados por outros, inclinados com fechamento em cunha (Fig. 4a). Interpretam-se esses refletores como feições que ocorrem em estratificações cruzadas, acanaladas, presentes nos arenitos da região.
$\mathrm{Na}$ Figura 4b, que apresenta o modelo interpretado da Linha 1 (Fig.4a), estão assinalados os elementos interpretados do radargrama. Dentre eles, ressaltam-se as fraturas, representadas em pontilhado preto, ocorrendo em material basicamente formado de areia.

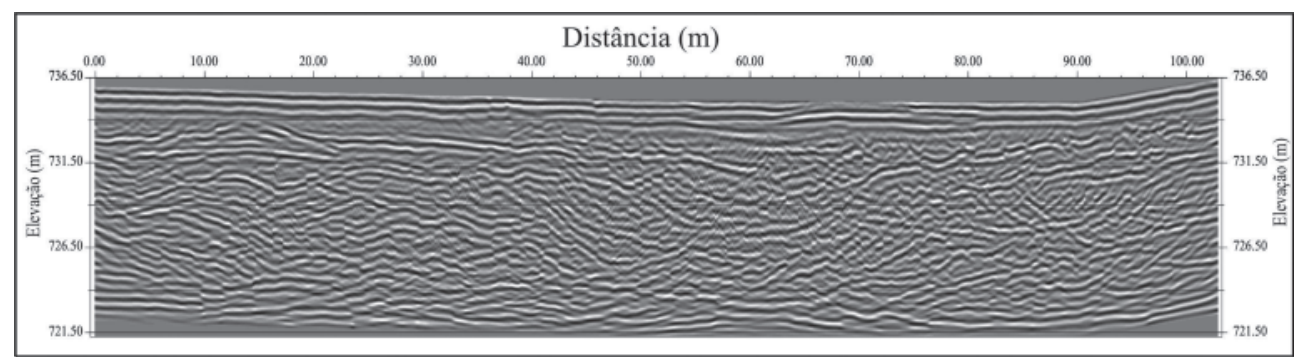

Figura 4 a - Radargrama da Linha 1 com Georadar, obtido na vereda do Jatobá.

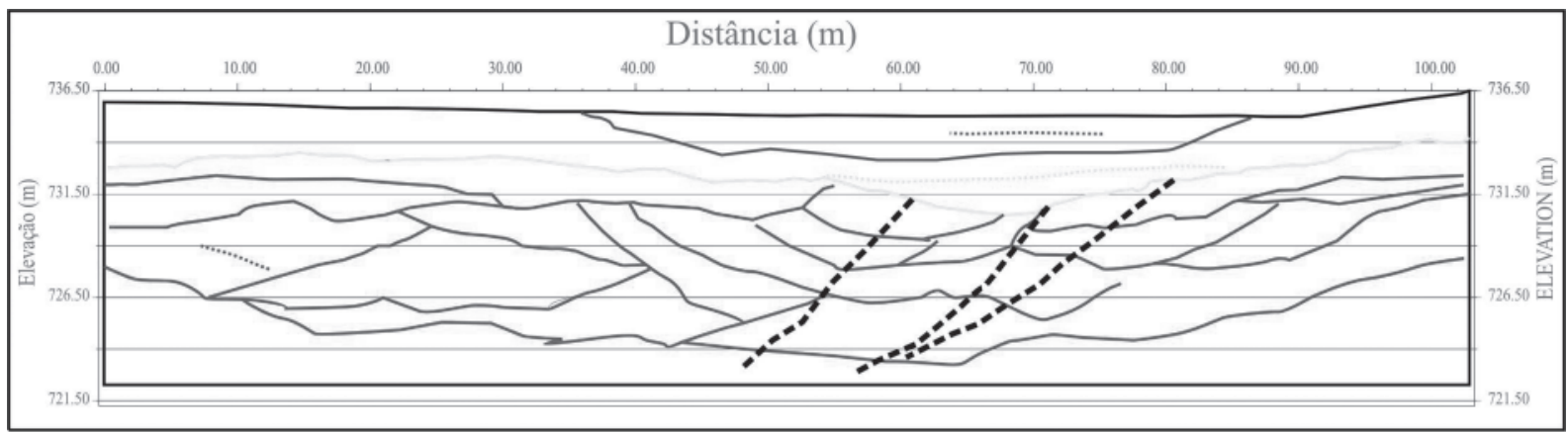

Legenda

_ Linha basal do Colúvio I

Linha basal do Colúvio II

- Estratificação cruzada no Arenito

......... Fratura

Figura 4 - Modelo da superfície ao longo da Linha 1, acima da cabeceira da Vereda Jatobá.

A linha 2 (Fig. 5), correspondente ao segundo transecto, realizado ao longo da cabeceira propriamente dita, ou seja, no segmento com a presença de buritis, encontra-se localizada a $729 \mathrm{~m}$ de altitude, entre $17^{\circ} 14^{\prime} 21.5^{\prime \prime} \mathrm{S}$ e W $45^{\circ} 07^{\prime} 53.1$ W. Ao longo dela foram realizados três perfis de solo, bem como um transecto do Georadar. Enquanto o solo da margem direita (Tab.1), cujo perfil $(45 \mathrm{~cm})$ foi aberto na parte mais elevada da borda da vereda (2.1. a-b-c), demonstra predominância quase total da areia com traços de matéria orgânica em todos os seus volumes, o da zona do fundo do canal (2.2 a-b), após $80 \mathrm{~cm}$ de material arenoso, torna-se argiloso e bastante escuro, associado ao aumento do percentual de matéria orgânica $(27,5 \%)$ nesse material que pode ser considerado como turfa.

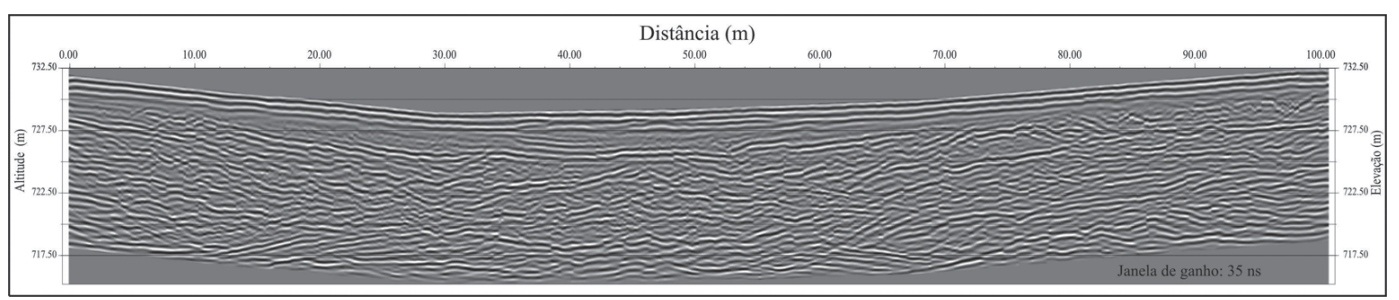

Figura 5 - Radargama da Linha 2, na cabeceira da Vereda. 
O nível freático foi detectado a $1,88 \mathrm{~m}$, demonstrando que se encontra muito mais profundo do que na zona localizada à 50m do início da cabeceira. Esse fato, associado ao espesso pacote de areia $(85 \mathrm{~cm})$ sobre a turfa, indica a existência de processo de assoreamento responsável pelo soterramento da zona central do canal da vereda e pelo fato do nível freático encontrar-se tão profundo. A transição abrupta e plana entre o solo hidromórfico na base e o colúvio, no topo, aponta para a ocorrência de evento rápido de deposição, o que impediu interdigitação ou mistura entre o material mais avermelhado e argiloso do colúvio, e o arenoso do solo hidromórfico. A geometria dos refletores da Linha 2 (Fig. 5), na parte superior, indica a existência de abaulamento do leito da vereda, associado à ocorrência de alternância de períodos de erosão e deposição.

Foi aberto apenas um perfil de solo no fundo da vereda (zona central) ao longo do terceiro transecto. O material é argiloso, muito rico em matéria orgânica, sendo que o segundo volume pode ser classificado como turfa. De todos os perfis, este parece se enquadrar nas descrições mais clássicas das áreas hidromórficas das veredas, identificadas por Melo (1992), como uma zona de campo higrófilo, rico em ciperáceas na média/baixa vertente, onde o horizonte superficial, rico em matéria orgânica é mais espesso em direção à base da vertente e há a presença de uma zona encharcada, com a ocorrência de solos turfosos, onde se destaca a palmeira "buriti". No entanto, em função do impacto já detectado nessa vereda, o nível freático não aflora, tendo sido observado há $2,5 \mathrm{~m}$ de profundidade.

$\mathrm{O}$ radargrama desse transecto (T2) indica uma concavidade mais pronunciada do que a do primeiro radargrama, coincidindo com a porção central do "canal" da vereda.
O perfil de solo aberto nessa porção permitiu a identificação de dois volumes pedológicos bastante distintos, o que pode ser também identificado no radargrama pelas características dos refletores, abaulados e contínuos. Esses marcam exatamente a diferença dos níveis diferentes, esses dois volumes. Na parte inferior aparece o mesmo padrão identificado no primeiro radargrama, refletores inclinados e descontínuos, os quais foram correlacionados com a estrutura da areia da Formação Areado (estratificação cruzada), portanto caracterizando a presença de material "in situ". As linhas difusas logo abaixo do limite entre os volumes pedológicos, parecem, por outro lado, estar associadas à ocorrência do nível freático, já bastante rebaixado em função do impacto antrópico nessa vereda.

O perfil da Linha 3 (Fig. 6 a) foi realizado entre as porções média e baixa da vereda. Houve a abertura de apenas um perfil de solo, no fundo do "canal" da vereda, na zona de solos hidromórficos pouco assoreados e apresentando falhas no renque de buritis, atualmente usado para pastejo melhorado, com o plantio de braquiária.

Com profundidade de $2,50 \mathrm{~m}$ apresenta sequência de quatro isovolumes e parece representar o típico solo hidromórfico e camada tampão, responsável pela retenção da água na e próxima à superfície, típica das veredas. Os primeiros $5 \mathrm{~cm}$ são formados por um colúvio argiloso, com estrutura granular e cor (seca) Bruno-avermelhado escuro (5YR 3/3), com 23.5\% de matéria orgânica, e umidade atual de 11.3 (após as primeiras chuvas de outubro). A presença desse colúvio pouco espesso indica que esta zona, em função possívelmente da densa (ainda) cobertura vegetal, encontrase relativamente protegida da erosão identificada nas bordas da vereda.

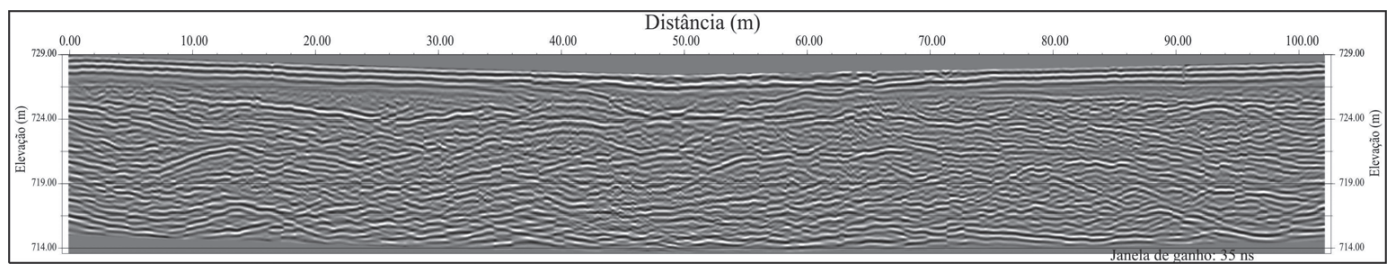

Figura 6a - Radargrama da Linha 3, médio curso da vereda

40

50

60

70

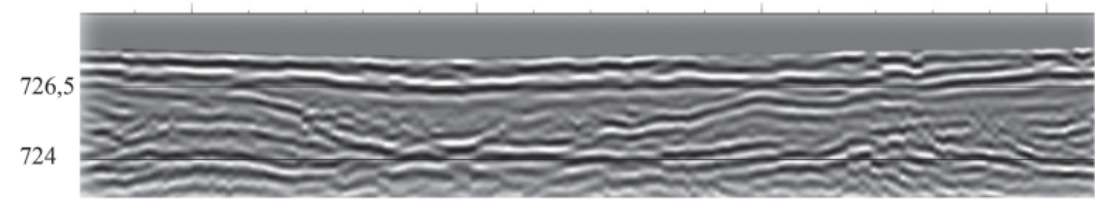

Figura 6 - Detalhe do radargrama da Linha 3, entre as distâncias de 38 e 71m, até uma profundidade máxima de $4 m$. 
O segundo volume tem $50 \mathrm{~cm}$ de espessura, cor preta (GLEY 2.5/N), textura muito argilosa com $28.6 \%$ umidade de matéria orgânica e $114.7 \%$ de umidade atual. Este volume, portanto, pode ser considerado como turfa, em função do percentual de matéria orgânica.

O volume 3 conta com uma espessura e com textura argilosa semelhantes às do segundo isovolume, mas a cor é preto-azulada (GLEY 2.5/PB) e a percentagem de matéria orgânica $(16.4 \%)$ e umidade atual são mais baixas $(92,0)$. O volume 4 , com um metro de espessura, apresenta textura argilosa (17.4\%) e 80.6 de umidade atual. A cor escuro-azulada indica a presença de matéria orgânica, com a presença de argila, em condições de drenagem pobre. De fato, o nível freático, observável pelo excesso de água na sondagem por trado, foi encontrado a $2,05 \mathrm{~m}$ de profundidade.

O radargrama desse perfil mostra uma evolução mais complexa do que os anteriores, em especial na porção central da vereda. Lateralmente observa-se o abaulamento do "canal", abaulamento este que se torna difuso na porção central, indicando possívelmente sequências de entulhamento e retrabalhamento dos sedimentos pela água do canal, mesmo sob condições de baixa energia.

Isto levanta a questão se essas depressões constituiriam "pseudo-dolinas", desenvolvidas pela dissolução da sílica, que em condições de umidade permanente e baixa energia teriam encontrado saída e se estruturado em redes de drenagem. Uma vez formada a depressão e havendo acumulação de água, independentemente do mecanismo envolvido, como por exemplo, a existência de camada tampão ou silicificação do arenito em profundidade, existe uma tendência da água em buscar saída, o que leva à organização de drenagem em fluxos.

No quarto transecto (a $400 \mathrm{~m}$ da cabeceira) foram abertos três perfis de solo: dois na borda direita da vereda, sendo um na alta e outro na média vertente e o terceiro no fundo do canal. O solo ( $1 \mathrm{~m}$ de espessura) localizado mais no alto é formado basicamente por areia (gley), com enriquecimento de matéria orgânica. O da média vertente é mais estruturado, apresentando dois isovolumes, um argilo-arenoso e o outro de areia, ambos escuros e com evidências de drenagem pouco efetiva. $O$ terceiro perfil foi aberto no fundo do canal da vereda e é formado por argila escura, Gley, com a presença de matéria orgânica e de água sazonal. A ocorrência de solo hidromórfico com transição difusa entre os dois isovolumes aponta para a ocorrência de processos lentos de deposição e de pedogênese do material, em situação de baixo turbilhonamento da água para que esses processos pudessem ocorrer.

Existe $15 \mathrm{~m}$ de intervalo entre os radargramas das Linhas 4D e 4E (Fig. 7 a e 7b). Eles mostram que a vereda, nesse trecho, passou por diversas fases de ajuste da zona preferencial de escoamento (canal). Lateralmente, nos dois sentidos, é possível detectar a presença de uma zona de deposição com início de abaulamento, que se encontra mais claramente definida na zona central da vereda.
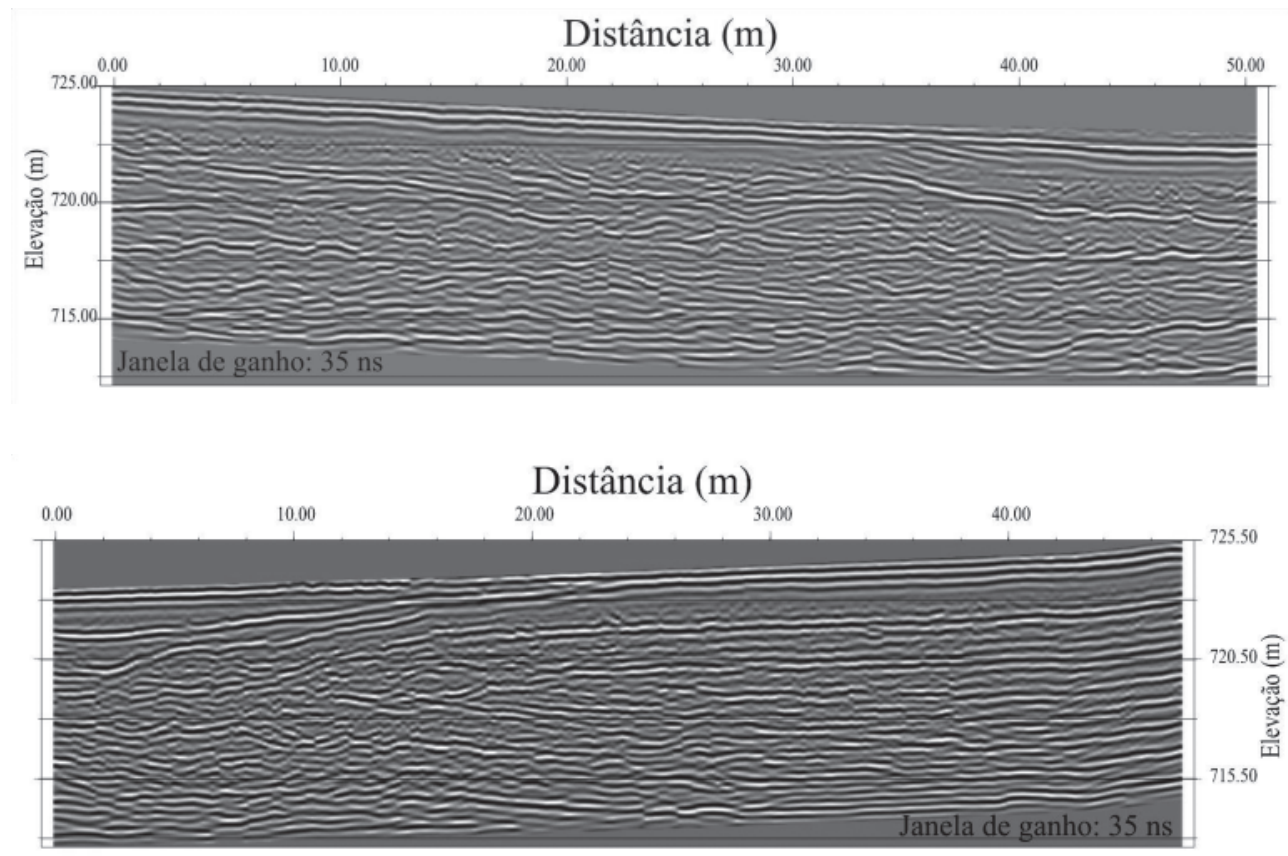

Figura 7 - Radargramas na parte final da Vereda Jatobá: a) Radargrama da Linha 4E; b) Radargrama da Linha 4D. 
É possível observar-se na zona central, a ocorrência de mais do que uma estrutura profunda e côncava, indicando que a vereda passou, em tempos pretéritos, por pelo menos duas fases de encaixe e assoreamento. Essas feições, aparentemente, demonstram tentativas de encaixe do canal, que parece ter vagado por uma área lateral muito maior do que a que ocupa atualmente. Depois do encaixe, a ocorrência de deposição, incisão, deposição e novamente incisão pode ser interpretada como resultantes, possivelmente, de condições de baixa energia hidráulica, anteriores à formação completa da vereda.

Segundo Augustin (2008), para o desenvolvimento da vereda, é fundamental a ocorrência de um ambiente hidrológico relativamente tranquilo, com baixa capacidade erosiva do fluxo de água, que permita a deposição da matéria orgânica e argila. Declividades muito acentuadas exercem um profundo impacto sobre essa dinâmica hidrológica, pois aceleram a velocidade da água, aumentando sua capacidade erosiva e originando um fluxo que tende a dissecar as camadas orgânicas, atingindo horizontes mais profundos e mais susceptíveis à erosão. Uma vez desenvolvido um canal mais profundo, a tendência é de que a vegetação do ecossistema original se modifique e que espécies do cerrado, cerradão e mesmo de matas ciliares passem paulatinamente a substituir àquelas típicas das veredas.

Portanto, para que a vegetação dos ecossistemas originais se mantenha, é necessária a presença de uma zona úmida, com uma camada de matéria orgânico-argilosa. Segundo observações realizadas no campo, esse material argilo-orgânico funciona como camada tampão, impedindo o esvaziamento da zona saturada e de baixa energia hidráulica. Há indícios de que esses lençóis freáticos são do tipo suspenso (perched water table), de caráter mais local, sem que apresentem interligações, como acontece com os lençóis regionais.

Os lençóis suspensos tendem a se formar e desenvolver em função tanto da declividade pouco acentuada do canal longitudinal e das bordas das veredas, como da ocorrência de espessas camadas de areia que filtram a matéria orgânica e desaceleram a velocidade da água de superfície e de subsuperfície, contribuindo para a retenção das mesmas. Essa capacidade de retenção afeta também as argilas, fazendo com que se acumulem e formem "camadas tampões" impedindo que a água armazenada seja drenada. É possível que a silicificação das areias em profundidade também contribua para a retenção do nível freático. Contudo, as imagens dos radargramas demonstram a ocorrência de intenso fraturamento das rochas, indicando perda da capacidade de retenção da água e formação de níveis freáticos. Outra possibilidade para a formação desses níveis, no entanto, pode estar associada à diminuição do diâmetro das areias em profundidade.
Boaventura (1988), em estudo de casos, apresenta o conceito geral de veredas como sendo vales rasos, com vertentes côncavas suaves, cobertas por solos argilosos, frequentemente turfosos. Os dados levantados no estudo dessa vereda demonstram que essas feições não são encontradas mais em sua plenitude. O nível freático, por exemplo, já não aflora em toda a sua extensão, pois se encontra frequentemente soterrado por sedimentos, enquanto entre a zona encharcada, pantanosa e a zona de cerrados adjacentes, ocorrem zonas arenosas com espécies do cerrado colonizando áreas da vegetação rasteira original.

\section{Conclusão}

Os dados deste estudo indicam variações na estrutura subsuperficial e na presença da água ao longo da vereda Jatobá, típica do norte de Minas Gerais. As transformações identificadas têm tanto caráter antrópico, como natural, conforme detectado no último transecto (radargrama).

Quanto ao impacto antrópico, observa-se que toda a comunidade hidrófila típica das veredas começa a apresentar sinais de degradação generalizada. As condições para a manutenção do equilíbrio hídrico-pedogeomorfológico, fundamental para garantir esse ecossistema, estão sendo alteradas. Pouco se conhece sobre a capacidade regenerativa dos mesmos e as consequências diretas e indiretas do desaparecimento ou degradação muito intensa das veredas na rede de drenagem do norte de Minas Gerais, pois elas constituem os principais contribuintes dos rios mais importantes da área.

Os dados ainda apontam para a existência de níveis freáticos suspensos (perched water tables), de caráter local, levando a crer que os impactos ambientais negativos possam ainda ser mais graves do que aqueles em áreas com afloramento dos níveis freáticos regionais.

No que se refere ao impacto natural, os radargramas e os dados direto dos solos, indicam a ocorrência de diferentes tentativas de escavamento de um canal principal durante a evolução da vereda, embora não tenha sido possível estabelecer se isto ocorreu já com a presença dos ecossistemas típicos. Os dados apontam, também, a ocorrência de processos recentes de assoreamento dessa vereda, provocando o rebaixamento aparente do seu nível freático. Esse rebaixamento pode ser aparente porque, na realidade, este se encontra soterrado pela grande quantidade de material trazido por erosão ocorrente tanto à montante, quanto nas bordas da vereda.

Ressalta-se, portanto, a necessidade de estudos mais aprofundados sobre estes geo-ecossistemas, para que seja possível uma melhor compreensão de sua dinâmica hídrigeomorfológica. Somente obtendo-se uma compreensão mais aprofundada do seu papel ambiental, será possível a adoção de políticas de uso e ocupação adequadas das áreas de ocorrência das veredas. 


\section{Referências Bibliográficas}

ARANHA, P.R.A. Estudo das coberturas superficiais e sua dinâmica na região de Gouveia, Serra do Espinhaço, MG: utilizando o Radar de Penetração no Solo (GPR). Tese de Doutorado, UFOP, Ouro Preto, 305p, 2003.

ARANHA, P.R.A., AUGUSTIN, C.R.R. \& SOBREIRA, F.G. Aplicações do Geo-radar no estudo geomorfológico em Gouveia, Serra do Espinhaço MG. In: Congresso Internacional de Geofísica Sociedade brasileira de Geofísica, Rio de Janeiro. Anais ... 2003. Vol.1, p.14-18. Rio de Janeiro.

AUGUSTIN, C.H.R.R., Notas de trabalhos e campo nas regiões de Veredas em Minas Gerais. (Informações Verbais). 2008.

AUGUSTIN, C.H.R.R., MELO, D.R. \& ARANHA, P.R.A. Aspectos da evolução geomorfológica das veredas no norte de Minas Gerais. In: VII SINAGEO, II Encontro Latino Americano de Geomorfologia, Belo Horizonte. Anais... UGB-IGC/UFMG, 2008. Vol. 1, Eixo 4, p.1-19.

AUGUSTIN, C.R.R.R., ARANHA, P.R. A.A \& COLTRINARI, L. Contribution of gullies for geochemical and physical losses from a small catchment area in the humid tropics (Minas Geris, Brazil). In: 6th International Conference on Geomorphology. Zaragoza, 2005. Anais... International Association of Geomorphology, 2005. Vol. 1. p.39-39.

BAGGIO FILHO, H. Alterações na paisagem natural e agrícola do Município de Buritizeiro - MG: implicações do plantio generalizado de Eucaliptos e Pinus no meio ambiente físico, biológico e sócio/ econômico. 2002. 149f. Dissertação Mestrado em Geografia-Instituto de Geociências, Universidade Federal de Minas Gerais, Belo Horizonte. 2002

BARBOSA, G.V. Relevo. In: BANCO DE DESENVOLVIMENTO DE MINAS GERAIS. Diagnóstico da economia mineira: o espaço natural. Belo Horizonte:BDMG, 1967. v2. p.69108.

BENSON, A.K. Applications of GPR in assessing some geological hazards: examples of ground water contamination, faults, cavities. Journal of Applied Geophysics, 1995. V.33, p.177-193.

BOAVENTURA, R.S. Preservação das veredas: síntese. In: Encontro Latino Americano Relação Ser HumanoAmbiente, 2., 1998, Belo Horizonte. Anais...Belo Horizonte. FUMEC, 1998, p. 109-118.
Contribuição aos estudos sobre a evolução das veredas. In:. Características geomorfológicas. In: Fundação Centro Tecnológico de Minas Gerais (CETEC). Plano de Desenvolvimento Integrado do Noroeste Mineiro, Vol. 2: Recursos Naturais. Belo Horizonte. CETEC, 1981.

Contribuição aos estudos sobre a evolução das veredas. In:Encontro Nacional de Geógrafos, 3., Fortaleza. Anais...Fortaleza. AGB/UFC, 1978.

BRANCO, J. J. R. Roteiro geológico de Belo HorizonteBrasília. In: Roteiro Para Excursão Belo Horizonte-Brasília. Belo Horizonte, Instituto de Pesquisas Radioativas da UFMG, 1961. Publicação $\mathrm{n}^{\circ} 15$.

DAVIS, J.L. \& ANNAN, A.P. Ground penetrating radar for high resolution mapping of soil and rock stratigraphy. Geophysical Prospecting 37, p. 531 $-551,1989$.

FREYBERG, B.V. Ergebnisse forschungen in Minas Gerais (Brasília). Miner. Geol., Mimeografado apud BARBOSA, G. V. Relevo. In: BANCO DE DESENVOLVIMENTO DE MINAS GERAIS. Diagnóstico da Economia Mineira: Espaço Natural, Belo Horizonte: BDMG, 1967. v.2, p.69108.

FUNDAÇÃO CENTRO TECNOLÓGICO DE MINAS GERAIS. Plano de Desenvolvimento Integrado do Noroeste Mineiro, 2., Recursos Naturais. Belo Horizonte: CETEC, 1981.

HARA, T. \& SAKAYMA, T. The applicability of ground probing radar to site investigations. OYO, RP4159, 32 p. 1985.

HUGGENBERGER, P.; MEIER, E. \& PUGIN, A. Ground probing radar as a tool for heterogeneity estimation in gravel deposits: advances in data - processing and facies analysis. Journal of Applied Geophysics, 31, p.171 - 184. 1994.

LIMA, S. do C. As veredas do ribeirão Panga no Triângulo mineiro e a evolução da paisagem. 1996, 260f. Tese (Doutorado em Geografia física). Universidade de São Paulo, São Paulo. 1996.

MELO, D. R de. Evolução das Veredas sob Impactos Ambientais nos Geossistemas Planalto do Buritizeiro/MG. 2008, 353f. Tese de doutorado em Geografia, Instituto de Geociências-Universidade Federal de Minas Gerais. 2008. 
As veredas nos planaltos do Noroeste Mineiro: caracterizações pedológicas e os aspectos morfológicos e evolutivos. In: $7^{\circ}$ Simpósio Brasileiro de Geografia Física Aplicada, Curitiba, PR Anais...Curitiba:UFPR, 1997, Vol.2.

Contribuição ao estudo geomorfológico de veredas: região de Pirapora, MG. Monografia de Graduação em Geografia, Instituto de Geociências, Universidade Federal de Minas Gerais, Belo Horizonte. 48p. 1978.
As veredas nos planaltos do Noroeste Mineiro, caracterizações pedológicas e os aspectos morfológicos e evolutivos. 1992. 218f. Dissertação de Mestrado em Geografia. Departamento de Geografia e Planejamento Regional, Instituto de Geociências, Universidade Estadual de São Paulo, Rio Claro, SP, 1992.

VIANA, M. B. Programa de preservação de veredas na área de influência da UEH de Miranda. 1987, $25 f$. Monografia (Curso de Especialização em Análise Ambiental), Departamento de Geografia, Instituto de Geociências, Universidade Federal de Minas Gerais, Belo horizonte. 1987. 